\title{
Comparison and validation of 2 analytical methods for the determination of free fatty acids in dairy products by gas chromatography with flame ionization detection
}

\author{
David T. Mannion, ${ }^{*}$ Ambrose Furey, $\dagger$ and Kieran N. Kilcawley* ${ }^{* 1}$ \\ ${ }^{*}$ Teagasc Food Research Centre, Moorepark, Fermoy, Co. Cork, Ireland \\ †Cork Institute of Technology, Bishopstown, Cork, Ireland
}

\section{ABSTRACT}

Accurate quantification of free fatty acids (FFA) in dairy products is important for quality control, nutritional, antimicrobial, authenticity, legislative, and flavor purposes. In this study, the performance of 2 widely used gas chromatographic flame ionization detection methods for determination of FFA in dairy products differing in lipid content and degree of lipolysis were evaluated. We used a direct on-column approach where the isolated FFA extract was injected directly and a derivatization approach where the FFA were esterified in the injector to methyl esters using tetramethylammonium hydroxide as a catalyst. A comprehensive validation was undertaken to establish method linearity, limits of detection, limits of quantification, accuracy, and precision. Linear calibrations of 3 to $700 \mathrm{mg} / \mathrm{L}$ $\left(\mathrm{R}^{2}>0.999\right)$ and 20 to $700 \mathrm{mg} / \mathrm{L}\left(\mathrm{R}^{2}>0.997\right)$, and limits of detection and limits of quantification of 0.7 and $3 \mathrm{mg} / \mathrm{L}$ and 5 and $20 \mathrm{mg} / \mathrm{L}$ were obtained for the direct injection on-column and the derivatization method, respectively. Intraday precision of 1.5 to $7.2 \%$ was obtained for both methods. The direct injection on-column method had the lower levels of limits of detection and quantification, because FFA are directly injected onto the GC as opposed to the split injection used in the derivatization method. However, the direct injection on-column method experienced accumulative column phase deterioration and irreversible FFA absorption because of the acidic nature of the injection extract, which adversely affected method robustness and the quantification of some longer chain FFA. The derivatization method experienced issues with quantification of butyric acid at low concentrations because of coelution with the injection solvent peak, loss of polyunsaturated FFA due to degradation by tetramethylammonium hydroxide, and the periodic emergence of

Received December 22, 2015.

Accepted February 26, 2016.

${ }^{1}$ Correspondence author: kieran.kilcawley@teagasc.ie by-product peaks of the tetramethylammonium hydroxide reaction that interfered with the quantification of some short-chain FFA. The derivatization method is more robust, and because the derivatization step can be automated, it is more suitable for routine analysis of FFA in dairy products. However, considerable scope exists to develop an alternative gas chromatography with flame ionization detection method to quantify FFA in dairy products without any limitations that is robust and accurate.

Key words: free fatty acid, dairy, gas chromatography, methyl ester

\section{INTRODUCTION}

Free fatty acids (FFA) are an important class of compounds in food and dairy products from a flavor, nutritional, and antibacterial perspective. They have a large effect on organoleptic quality because of their low odor thresholds, especially the short-chain fatty acids, which provide the characteristic odors for many dairy products but are also responsible for rancidity defects. In the past the main requirement for the quantification of FFA was for quality control of milk and dairy products. Even though other chromatographic methods exist to quantify FFA, the most popular method of analysis involves gas chromatography with flame ionization detection (GC-FID) because of its precision and reliability and relative low cost (Christie, 1993; Delmonte et al., 2009). In the case of FFA they can be analyzed after conversion to methyl esters (Metcalffe and Wang, 1981; Needs et al., 1983; Martínez-Castro et al., 1986) or directly after extraction from the product (Woo and Lindsay, 1982; Deeth et al., 1983; De Jong and Badings, 1990). The isolation of FFA by aminopropyl solid-phase extraction (SPE) columns followed by GC-FID analysis is a widely used approach to quantify FFA (De Jong et al., 1994; Hickey et al., 2006, 2007; Kilcawley et al., 2012; Calzada et al., 2014). In this case all of the FFA are isolated with a reportedly high degree of purity (Kaluzny et al., 1985), and no further treatment is required before GC analysis, thus making it a convenient 
alternative to derivatized methods. For derivatization reactions, tetramethylammonium hydroxide (TMAH) is a commonly used derivatizing agent to convert FFA to FAME before GC-FID analysis (Martínez-Castro et al., 1986; Martin-Hernández et al., 1988; Juárez et al., 1992; Chavarri et al., 1997; Gomes Reis et al., 2011), because of its ability to simultaneously create methyl esters of glycerides and form salts of FFA (which are then converted to methyl esters in a heated injector) in separate phases. This makes it possible to analyze both components of the lipid extract without the need for prior separation.

Martínez-Castro et al. (1986) and De Jong and Badings (1990) have described some limitations in relation to both of these methods that need further investigation. Underivatized FFA have a strong interaction with column phases, which can lead to irreversible adsorption, a phenomenon referred to as "memory effect" that can result in overestimation of FFA content. Also, the direct injection method involves the isolation of FFA in $2 \%$ formic acid in diethyl ether, which is very acidic and has an adverse effect on column lifespan (De Jong and Badings, 1990). This can be very costly but also adversely affect the responses of analytes. Such drawbacks may also affect retention times, limits of detection (LOD), limits of quantification (LOQ), and linearity values. The use of TMAH as an esterification reagent for FFA also has limitations (Martínez-Castro et al., 1986); the glyceride component of extracted lipids was shown to interfere with FFA determination. This led Martínez-Castro et al. (1986) to modify the extraction steps to include solvent washing of the separate layers, to remove interfering compounds before analysis. This issue of glyceride interference was further highlighted by Chavarri et al. (1997), who reported a significant disagreement between the results obtained between FFA isolation using aminopropyl SPE columns and direct injection, and the derivatization method where FFA are converted into methyl esters using TMAH. They recommended isolating the FFA from the lipid extract before treatment with TMAH when analyzing samples with a large triglyceride-to-FFA ratio, which is the case with most dairy samples.

Oddly, very few studies have been published relating to the effectiveness, LOD, LOQ, linearity, and detection range of these routinely used methods in relation to dairy products, despite the fact that both have been in use for more than a couple of decades. Also, the practical application of these methods to quantify FFA in a range of different dairy sample matrices has not been fully explored. In addition, both of these methods are relatively laborious and time consuming and require a large of amount of solvents and reagents; thus, the incorporation of a degree of automation into the methodology would likely be of significant benefit. Therefore, this study investigated the performance of both the FAME method (using TMAH for FFA derivatization) and the direct injection method after SPE of FFA on a wide range of dairy products. A modification of the FAME method was employed based on the findings of Chavarri et al. (1997), where the FFA was initially isolated from the sample extract before conversion to methyl esters using TMAH. Automation was incorporated in standard preparation and FFA derivatization.

\section{MATERIALS AND METHODS}

\section{Materials}

Hexane, heptane, diethyl ether, formic acid, 25\% tetramethylammonium hydroxide in methanol (TMAH), butyric acid $\left(\mathrm{C}_{4: 0}\right)$, valeric acid $\left(\mathrm{C}_{5: 0}\right)$, caproic acid $\left(\mathrm{C}_{6: 0}\right)$, caprylic acid $\left(\mathrm{C}_{8: 0}\right)$, capric acid $\left(\mathrm{C}_{10: 0}\right)$, undecylic acid $\left(\mathrm{C}_{11: 0}\right)$, lauric acid $\left(\mathrm{C}_{12: 0}\right)$, myristic acid $\left(\mathrm{C}_{14: 0}\right)$, palmitic acid $\left(\mathrm{C}_{16: 0}\right)$, margaric acid $\left(\mathrm{C}_{17: 0}\right)$, stearic acid $\left(\mathrm{C}_{18: 0}\right)$, oleic acid $\left(\mathrm{C}_{18: 1}\right)$, linoleic acid $\left(\mathrm{C}_{18: 2}\right)$, and linolenic acid $\left(\mathrm{C}_{18: 3}\right)$ were purchased from Sigma-Aldrich (Dublin, Ireland). Certified FFA standard mix containing $\mathrm{C}_{4: 0}$ to $\mathrm{C}_{22: 0}$ free acids (GLC Reference standard 74 "Free acid") and FAME standard mix containing $\mathrm{C}_{4: 0}$ to $\mathrm{C}_{22: 0}$ methyl esters (GLC Reference Standard 74) were purchased from $\mathrm{Nu}$-Chek Prep Inc. (Waterville, MN). Aminopropyl cartridges (500 mg) were obtained from Agilent Technologies Ireland Ltd. (Little Island, Cork, Ireland).

\section{Samples}

Milk, whole milk powder, infant formula powder, yogurt, ice cream, Cheddar cheeses, blue cheese, processed cheese, Brie, enzyme modified cheeses (EMC), and butter were purchased from local commercial suppliers or local retail outlets.

Infant formula, milk powder, and EMC powder samples were stored under nitrogen in sealed containers at room temperature in darkness. Milk, yogurt, butter, EMC paste, and ice cream samples were transferred into sterile containers, which were frozen at $-18^{\circ} \mathrm{C}$ until required. All cheese samples were vacuum packed and frozen at $-18^{\circ} \mathrm{C}$.

\section{Instrumentation}

The FFA and FAME analyses were carried out on a Varian CP3800 gas chromatograph (JVA Analytical Ltd., Dublin, Ireland) equipped with a CP8400 au- 
Table 1. Operating conditions for the gas chromatography analysis of free fatty acids and FAME

\begin{tabular}{|c|c|c|}
\hline Item & Free fatty acids & FAME \\
\hline Detector & Flame ionization detector & Flame ionization detector \\
\hline Column & $\begin{array}{l}\text { CP FFAP CB capillary column }(30 \mathrm{~m} \times 250 \mu \mathrm{m} \times 0.32 \\
\mu \mathrm{m})^{2}\end{array}$ & $\begin{array}{l}\text { CP FFAP CB capillary column }(30 \mathrm{~m} \times 250 \mu \mathrm{m} \\
\times 0.32 \mu \mathrm{m})^{2}\end{array}$ \\
\hline Inlet temperature program & $25^{\circ} \mathrm{C}$ for $6 \mathrm{~s}$, then $30^{\circ} \mathrm{C} / \mathrm{min}$ to $250^{\circ} \mathrm{C}$ & $300^{\circ} \mathrm{C}$ \\
\hline Inlet liner & SPI direct liner ${ }^{2}$ & Split Gooseneck liner ${ }^{2}$ \\
\hline Injection volume & $0.5 \mu \mathrm{L}$ & $2.0 \mu \mathrm{L}$ \\
\hline Oven temperature program & $\begin{array}{l}40^{\circ} \mathrm{C} \text { for } 2 \mathrm{~min} \text {, then } 7.5^{\circ} \mathrm{C} / \mathrm{min} \text { to } 240^{\circ} \mathrm{C} \text {, held for } 23.33 \\
\min \end{array}$ & $\begin{array}{l}40^{\circ} \mathrm{C} \text { for } 2 \mathrm{~min} \text {, then } 7.5^{\circ} \mathrm{C} / \mathrm{min} \text { to } 240^{\circ} \mathrm{C} \text {, held } \\
\text { for } 7 \mathrm{~min}\end{array}$ \\
\hline Detector temperature & $300^{\circ} \mathrm{C}$ & $300^{\circ} \mathrm{C}$ \\
\hline Flow rate & $1.2 \mathrm{~mL} / \mathrm{min}$ & $1.2 \mathrm{~mL} / \mathrm{min}$ \\
\hline Run time & $52 \min$ & $35.67 \mathrm{~min}$ \\
\hline
\end{tabular}

${ }^{1}$ JVA Analytical Ltd. (Dublin, Ireland).

${ }^{2}$ Agilent Technologies Ireland Ltd. (Little Island, Cork, Ireland).

tosampler and flame ionization detector (FID) and equipped with a 1079 programmable temperature vaporization injector. The column was a CP FFAP CB capillary column $(30 \mathrm{~m} \times 250 \mu \mathrm{m}$ i.d., $0.32-\mu \mathrm{m}$ phase thickness; Agilent Technologies Ireland Ltd.). Operating conditions for the GC analysis for both FFA and FAME are shown in Table 1.

\section{Automated Standard Preparation and Sample Derivatization}

The 7696A Sample Prep Workbench (Agilent Technologies Ireland Ltd.) is a standalone instrument designed to perform automated sample preparation (Figure 1). It is equipped with 2 autosampler towers capable of the

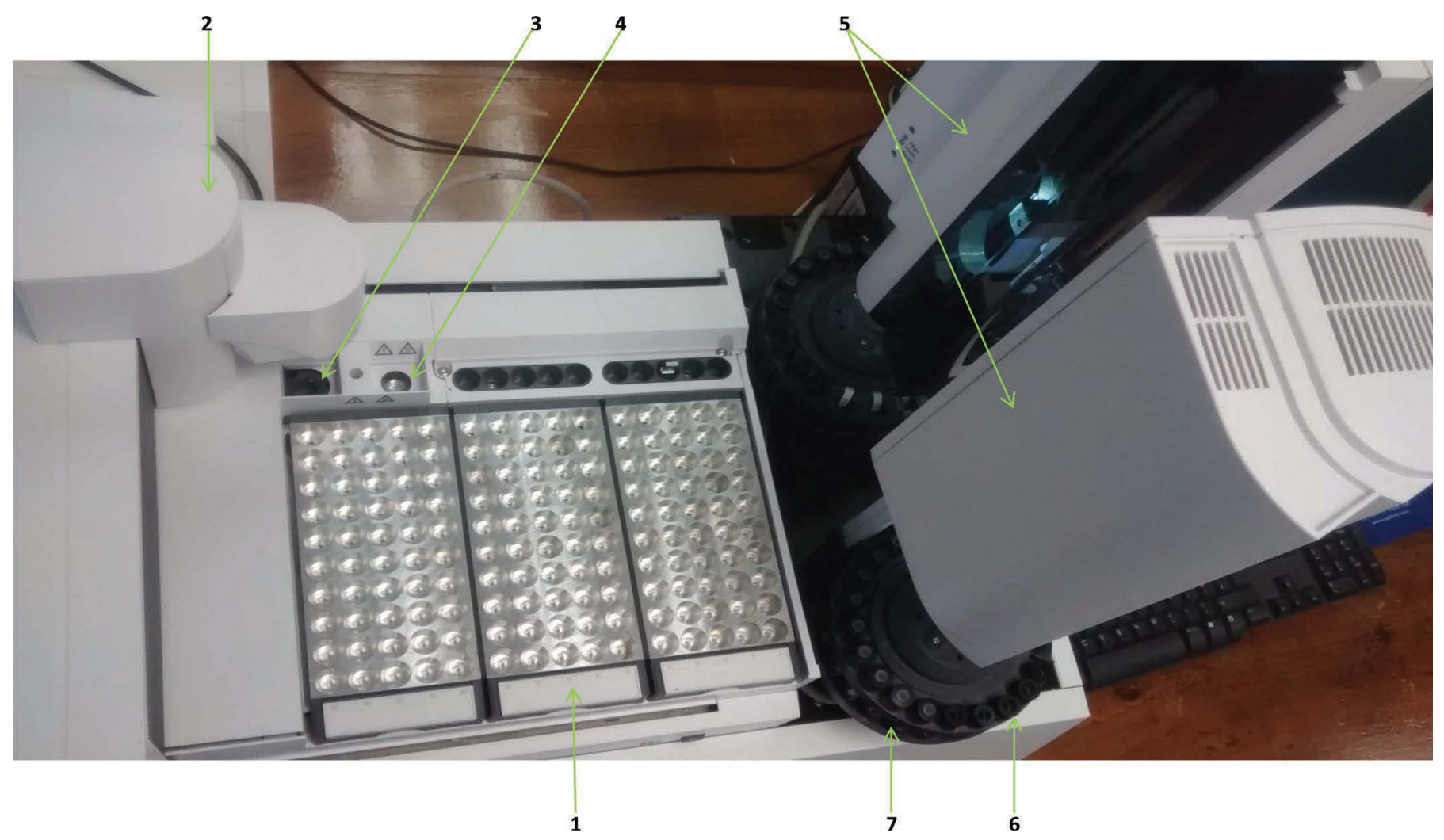

Figure 1. Schematic of Agilent Sample Prep Workbench System (Agilent Technologies Ireland Ltd., Little Island, Cork, Ireland). $1=$ sample trays; $2=$ robotic arm; $3=$ vial vortex; $4=$ vial heater; $5=$ auto-sampler towers; $6=$ waste vials; $7=$ solvent wash vials. 
volumetric transfer of liquids between 2 -mL vials. The sample tray consists of three 50-position trays, which are capable of refrigerating $\left(5^{\circ} \mathrm{C}\right)$ and heating (up to $80^{\circ} \mathrm{C}$ ), a vortex mixing station, a robotic arm, and a sample heating station. The ability to transfer liquids between vials allows the workbench to perform serial dilutions as well as the addition of reagents to a sample. It is also capable of performing phase separations where the sampling needle can be adjusted to take samples from the aqueous and organic layers separately. The workbench was employed in the preparation of all standards for calibration and validation studies, and for the derivatization reactions (methyl ester derivatization using TMAH). It was configured with a blue line $100-\mu \mathrm{L}$ gas tight syringe (Agilent Technologies Ireland Ltd.) in the back tower and a blue line $500-\mu \mathrm{L}$ gas tight syringe (Agilent Technologies Ireland Ltd.) in the front tower.

\section{Lipid Extraction}

Lipid extraction was carried out as per the procedure outlined by De Jong and Badings (1990) for FFA analysis in cheese samples, with the following modifications. For milk samples, $4 \mathrm{~mL}$ of sample was used for extraction. For EMC powder and paste samples, 0.5 $\mathrm{g}$ of sample was used. For all other sample types, $4 \mathrm{~g}$ was used. For Brie cheese samples, roughly $1 \mathrm{~cm}$ of the outer layer was removed before extraction. Blue cheese samples were blended thoroughly for $5 \mathrm{~min}$ to achieve a homogenous sample before extraction.

All samples were prepared by mixing with $10 \mathrm{~g}$ of anhydrous sodium sulfate with the exception of the EMC samples, where $1 \mathrm{~g}$ of anhydrous sodium sulfate was used. For the solid cheese samples, mixing was achieved through thorough grinding with a pestle and mortar. Solutions of $0.3 \mathrm{~mL}$ of $2.5 M^{M} \mathrm{H}_{2} \mathrm{SO}_{4}$ and $1 \mathrm{~mL}$ of internal standard (ISTD; $\mathrm{C}_{5: 0}, \mathrm{C}_{11: 0}, \mathrm{C}_{17: 0}$ at 1,000 $\mathrm{mg} / \mathrm{L}$ in heptane) were added to each sample mixture. This mixture was extracted 3 times with $15 \mathrm{~mL}$ of diethyl ether/heptane 1:1 (vol/vol), and each time the solution was clarified by centrifugation at $3,000 \times g$ at room temperature for $5 \mathrm{~min}$. The collected extracts were pooled for SPE.

\section{SPE}

Aminopropyl (500 mg) columns (Agilent Technologies Ireland Ltd.) were preconditioned with $10 \mathrm{~mL}$ of heptane. The lipid extract was applied to the column and the neutral lipids removed using $10 \mathrm{~mL}$ of $20 \%$ diethyl ether in hexane (at no point were the columns left to dry). The FFA were collected using $5 \mathrm{~mL}$ of $2 \%$ formic acid/diethyl ether $(2 \% \mathbf{F A} / \mathbf{D E})$ in glass test tubes. The entire extract was immediately separated and stored in 2-mL amber vials (Agilent Technologies Ireland Ltd.), which were capped with PTFE/white silicone septa (Agilent Technologies Ireland Ltd.). For the direct on-column injection method, $0.5 \mu \mathrm{L}$ of this solution was directly injected. In the derivatization method FAME, this solution was treated with TMAH according to the derivatization protocol described below.

\section{Methyl Ester Derivatization of Isolated FFA Using TMAH as a Catalyst}

The FFA extract $(300 \mu \mathrm{L})$ was transferred into a PTFE/white silicone capped 2-mL amber GC vial (Agilent Technologies Ireland Ltd.). The TMAH reagent $(60 \mu \mathrm{L})$ was added to the sealed vial containing the FFA extract. This was vortexed at 3,000 revolutions per minute for 1 min using a pulsed bidirectional spin of 5 s with a 1-s pause. Deionized water $(300 \mu \mathrm{L})$ was added to the mixture, and this was further vortexed for $1 \mathrm{~min}$ at 1,000 revolutions per minute. An aliquot of $100 \mu \mathrm{L}$ of this aqueous layer was transferred to a sealed GC vial containing a $250-\mu \mathrm{L}$ glass insert (Agilent Technologies Ireland Ltd.), and $2.0 \mu \mathrm{L}$ was injected onto the GC.

\section{Sample Analysis and Recovery Determination}

When carrying out both methods, the extraction procedures described (lipid extraction followed by SPE) were applied to 6 replicates $(n=6)$ of each sample. Three of these were unspiked, and 3 were spiked with a known amount of FFA. This FFA mixture contained all FFA $\left(\mathrm{C}_{4: 0}-\mathrm{C}_{18: 3}\right)$ at 1,000 $\mathrm{mg} / \mathrm{L}$ prepared in heptane, $0.5 \mathrm{~mL}$ were added to each sample during the mixing step with anhydrous sodium sulfate. The collected extracts of $5 \mathrm{~mL}$ of $2 \% \mathrm{FA} / \mathrm{DE}$ from the SPE step were analyzed directly in duplicate by GC-FID. For samples where the concentration was greater than the calibration range, the extract was diluted and reanalyzed until within range. Individual recoveries for each of the individual FFA compounds were calculated from the difference between the spiked and unspiked results.

\section{Standard Preparation}

All standard mixtures were prepared in heptane and stored at $-18^{\circ} \mathrm{C}$ until analysis. The maximum storage time was 6 mo. Prior to analysis the standard mixtures were sonicated at $40^{\circ} \mathrm{C}$ for $20 \mathrm{~min}$ to dissolve all the FFA. For instrument calibration, or when preparing standards for accuracy and precision studies, SPE was carried out as per the procedure described by De Jong 


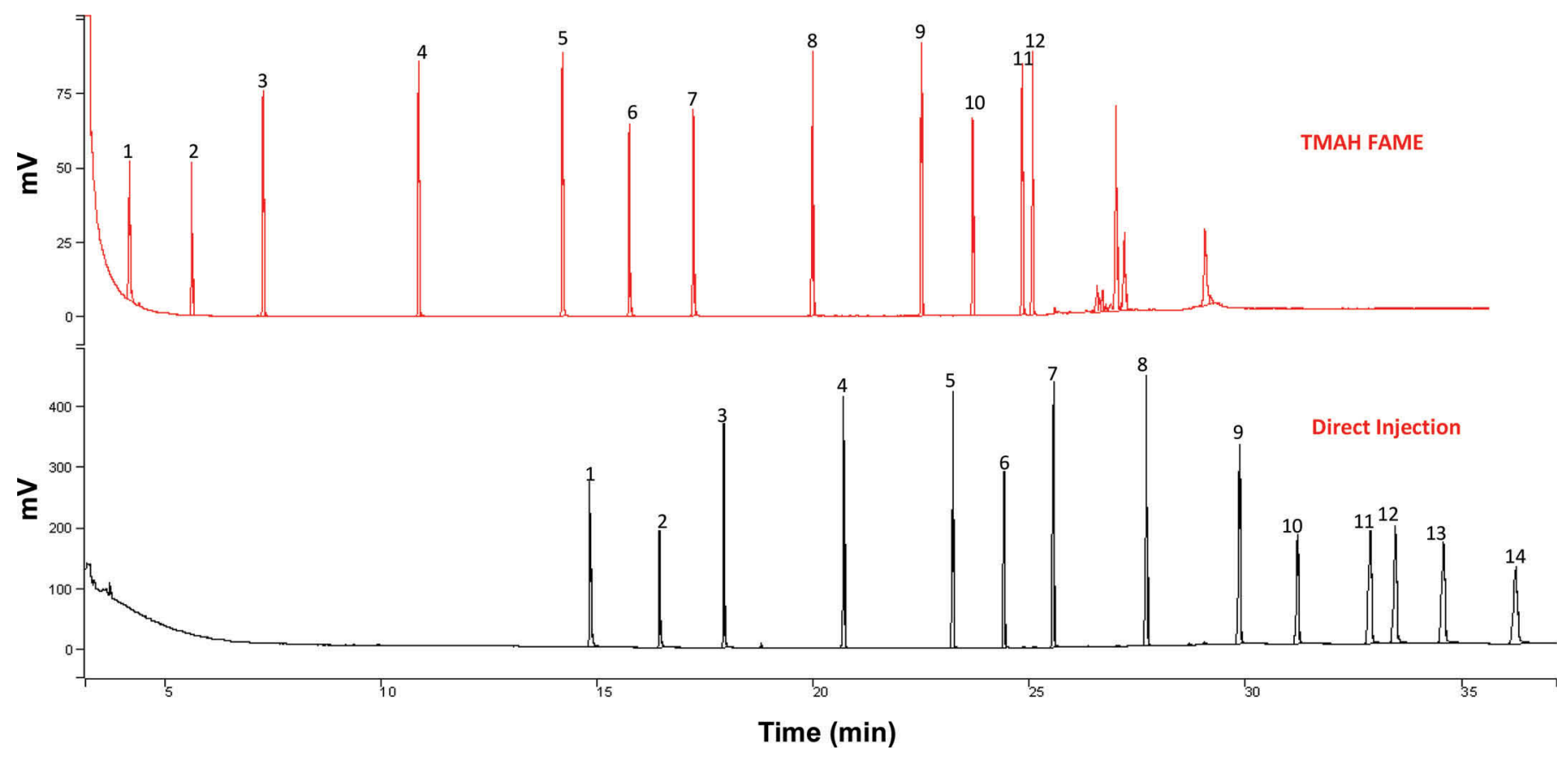

Figure 2. Chromatograms showing a typical standard mix of free fatty acids at $300 \mathrm{mg} / \mathrm{L}$ with internal standards (ISTD) at $200 \mathrm{mg} / \mathrm{L}$ for both methods. TMAH = tetramethylammonium hydroxide. The carbon number listed in the peak identification corresponds to the associated free fatty acid or methyl ester. Peaks are $1=\mathrm{C}_{4: 0} ; 2=\mathrm{C}_{5: 0}\left(\right.$ ISTD) $; 3=\mathrm{C}_{6: 0} ; 4=\mathrm{C}_{8: 0} ; 5=\mathrm{C}_{10: 0} ; 6=\mathrm{C}_{11: 0}$ (ISTD); $7=\mathrm{C}_{12: 0} ; 8=\mathrm{C}_{14: 0} ; 9=$ $\mathrm{C}_{16: 0} ; 10=\mathrm{C}_{17: 0}$ (ISTD); $11=\mathrm{C}_{18: 0} ; 12=\mathrm{C}_{18: 1} ; 13=\mathrm{C}_{18: 2} ; 14=\mathrm{C}_{18: 3}$. Note: Peaks 13 and 14 are not detected in FAME analysis. Color version available online.

and Badings (1990). The standards were collected in $2 \%$ FA/DE. Calibration curves were established using the Nu-Chek certified FFA calibration mix (Nu-Chek Prep Inc.). The necessary dilutions were carried out using the sample prep workbench, with the ISTD during the dilution step. Five point calibration curves were established with a concentration range of 3 to $700 \mathrm{mg} / \mathrm{L}$ for all FFA with the ISTD $\left(\mathrm{C}_{5: 0}, \mathrm{C}_{11: 0}\right.$, and $\left.\mathrm{C}_{17: 0}\right)$ at a concentration of $200 \mathrm{mg} / \mathrm{L}$.

For FAME analysis, the FFA calibration mix was collected in $2 \% \mathrm{FA} / \mathrm{DE}$ and derivatized according to the TMAH procedure as previously described using $300 \mu \mathrm{L}$ of the standard mix stock solution. The necessary dilutions were carried out before derivatization with the ISTD added during the dilution step using the sample prep workbench. The concentration range established for FAME analysis was 20 to $700 \mathrm{mg} / \mathrm{L}$ with the ISTD at $200 \mathrm{mg} / \mathrm{L}$.

Calibration curves were established based on the correction factors against each ISTD $\left(\mathrm{C}_{5: 0}, \mathrm{C}_{11: 0}\right.$, and $\mathrm{C}_{17: 0}$ ). These 3 ISTD were selected based on suitability to best account for the range of solubility and volatility of FFA found in dairy products. The short-chain acids $\left(\mathrm{C}_{4: 0}, \mathrm{C}_{6: 0}\right.$, and $\left.\mathrm{C}_{8: 0}\right)$ were calculated against $\mathrm{C}_{5: 0}$. The mid-chain-length acids $\left(\mathrm{C}_{10: 0}, \mathrm{C}_{12: 0}\right.$, and $\left.\mathrm{C}_{14: 0}\right)$ were calculated against $\mathrm{C}_{11: 0}$. The long-chain acids $\left(\mathrm{C}_{16: 0}, \mathrm{C}_{18: 0}\right.$, $\mathrm{C}_{18: 1}, \mathrm{C}_{18: 2}$, and $\mathrm{C}_{18: 3}$ ) were calculated against $\mathrm{C}_{17: 0}$.

\section{RESULTS AND DISCUSSION}

Typical chromatograms of FFA and FAME analysis of a standard mix are shown in Figure 2 and of a sample of mild Cheddar in Figure 3. These figures highlight the separation achieved of $\mathrm{C}_{4: 0}$ to $\mathrm{C}_{18: 3}$ on a 30-m FFAP column.

\section{Validating Extraction of FFA Using Solid-Phase Extraction: Aminopropyl Column Breakthrough Study}

Initially the breakthrough capacity of the 500-mg aminopropyl SPE cartridges was evaluated across the range of samples. The greater the fat content, the greater the potential to overload the aminopropyl phase, resulting in loss (breakthrough) of FFA during the procedure. The volume of the aminopropyl cartridges used in this study was $500 \mathrm{mg}$, and the typical sample weight employed was $4 \mathrm{~g}$. The fat content of a given sample can vary from a maximum of approximately $4 \mathrm{~g}$ for butter to much less in the other dairy samples.

This trial involved analyses of standard mixes containing both FFA and triacylglycerides to best mimic a typical sample lipid extract. For the study the concentrations of the FFA in the standards were kept constant (1 mg of each FFA standard), and the levels of 


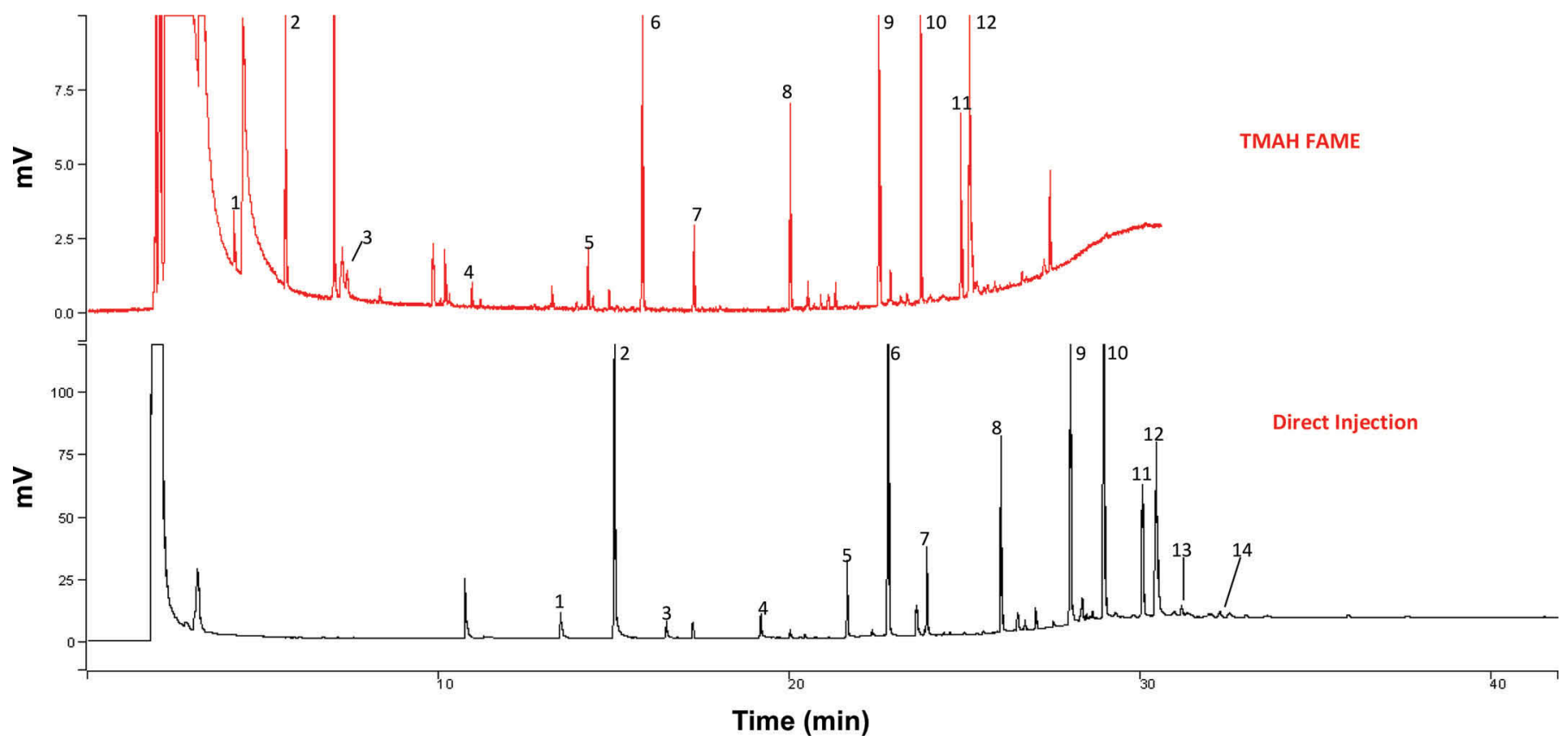

Figure 3. Chromatograms showing free fatty acid (FFA) and FAME analysis of mild Cheddar cheese. TMAH = tetramethylammonium hydroxide. The carbon number listed in the peak identification corresponds to the associated FFA for the FFA analysis or to the methyl ester for the FAME analysis. Peaks are $1=\mathrm{C}_{4: 0} ; 2=\mathrm{C}_{5: 0}$ (internal standard; ISTD); $3=\mathrm{C}_{6: 0} ; 4=\mathrm{C}_{8: 0} ; 5=\mathrm{C}_{10: 0} ; 6=\mathrm{C}_{11: 0}$ (ISTD); $7=\mathrm{C}_{12: 0} ; 8=$ $\mathrm{C}_{14: 0} ; 9=\mathrm{C}_{16: 0} ; 10=\mathrm{C}_{17: 0}$ (ISTD); $11=\mathrm{C}_{18: 0} ; 12=\mathrm{C}_{18: 1} ; 13=\mathrm{C}_{18: 2} ; 14=\mathrm{C}_{18: 3}$. Note: Peaks 13 and 14 are not detected in FAME analysis. Color version available online.

triacylglycerides were increased from $1.2 \mathrm{~g}$ (equivalent of a sample with $<30 \%$ fat content) to $4 \mathrm{~g}$ (equivalent to $100 \%$ fat content). Free fatty acids were selected to cover the range of polarities and chain lengths typically found in dairy fat: butyric acid $\left(\mathrm{C}_{4: 0}\right)$, capric acid $\left(\mathrm{C}_{10: 0}\right)$, and palmitic acid $\left(\mathrm{C}_{16: 0}\right)$. The $\mathrm{SPE}$ was carried out as per the De Jong and Badings (1990) procedure, and FFA were analyzed by direct on-column injection method. The FFA levels quantified were consistent regardless of the amount of triacylglycerides present, as shown in Supplemental Figure S1 (http://dx.doi. org/10.3168/jds.2015-10795). It can be concluded that, regardless of the fat content, the breakthrough capacity of the 500-mg aminopropyl columns was not exceeded under the experimental conditions applied.

\section{Optimization of the Direct Injection On-Column Method}

Retention Time Shift of Analyte Peaks. During the analyses a significant shift of retention times of all FFA peaks was observed using this method; the peaks eluted progressively earlier as the number of injections increased (Supplemental Figure S2; http://dx.doi. org/10.3168/jds.2015-10795). This appears to be due to the acidic nature of the $2 \% \mathrm{FA} / \mathrm{DE}$ solution resulting in degradation of the column phase, which leads to less phase interaction with the target analytes after each subsequent injection. Because of the severity of the retention time shift, it would be very difficult to establish a validated protocol based on retention times for this method. An effort was made to monitor the retention time shift, to establish approximately the length of time before it would be necessary to recalibrate the method. Supplemental Table S1 (http://dx.doi.org/10.3168/ jds.2015-10795) shows the retention times obtained from a FFA calibration mix analyzed roughly during the mid lifetime of the column. The procedure involved monitoring the retention times of all FFA, which were prepared in $2 \% \mathrm{FA} / \mathrm{DE}$ for analysis over a 72 -h period where the standard deviation of the retention times over this period was calculated. Supplemental Table S2 (http://dx.doi.org/10.3168/jds.2015-10795) shows the retention times obtained from an analysis of 10 samples, with blanks of $2 \% \mathrm{FA} / \mathrm{DE}$ injected between each sample. Using these thresholds, by the fifth sample (ninth injection including standards and blanks), the retention times shifted outside the acceptable limits (0.01-0.05 min) to correctly quantify most FFA. For routine sample analysis this would require a check standard to be run after every fifth sample in a batch to realign the retention times for quantification; this is a major limitation of this method.

Assessment of FFA Interaction with Column Phase. De Jong and Badings (1990) highlighted that FFA interact strongly with the FFAP column phase, 
leading to adsorption (memory effect) in the direct injection on-column method, which we also observed (FFA peaks were detected in blank injections). We also noted a significant variance in the analysis of FFA depending on whether they were prepared in heptane or $2 \% \mathrm{FA} / \mathrm{DE}$, with the analysis using $2 \% \mathrm{FA} / \mathrm{DE}$ solution yielding a significantly greater response. This led to the assumption that the $2 \% \mathrm{FA} / \mathrm{DE}$ solution inhibits FFA interaction with the column phase, resulting in more FFA traveling to the detector and thus an increased response. This memory effect poses problems for method accuracy, and the use of $2 \% \mathrm{FA} / \mathrm{DE}$ may create errors if the calibration solutions were prepared and analyzed in a typical organic solvent, such as heptane as described for standard preparation in the De Jong and Badings (1990) study.

A series of studies were undertaken to investigate the effect of $200 \mathrm{mg} / \mathrm{L}\left(\mathrm{C}_{5: 0}, \mathrm{C}_{11: 0}\right.$, and $\left.\mathrm{C}_{17: 0}\right)$ standards prepared in heptane or $2 \% \mathrm{FA} / \mathrm{DE}$ on FFA recovery (Supplemental Table S3; http://dx.doi.org/10.3168/ jds.2015-10795). The FFA quantification was achieved using a calibration curve constructed from serial dilutions of a standard prepared (50-400 $\mathrm{mg} / \mathrm{L}$ ) in heptane. A variance in the results was evident between standards prepared in heptane and 2\% FA/ DE. The measurements of the standards prepared in heptane (Supplemental Table S3 a-c; http://dx.doi. org/10.3168/jds.2015-10795) very closely matched the anticipated $200 \mathrm{mg} / \mathrm{L}$ value; however, the responses of the $\mathrm{C}_{11: 0}$ and $\mathrm{C}_{17: 0}$ standards prepared in $2 \% \mathrm{FA} / \mathrm{DE}$ (Supplemental Table S3 d-f; http://dx.doi.org/10.3168/ jds.2015-10795) were as high as $300 \mathrm{mg} / \mathrm{L}$. This increase is due to the $2 \% \mathrm{FA} / \mathrm{DE}$ reducing the adsorption of FFA onto the column phase, resulting in more of the FFA traveling through the column to the detector, giving an increased response. When introducing FFA in heptane, loss of FFA is higher because of adsorption, which results in a lower response. The $\mathrm{C}_{5: 0}$ standard yielded comparable average measurements $(201 \mathrm{mg} / \mathrm{L}$, $203 \mathrm{mg} / \mathrm{L}$ ) between the 2 solutions, with the measured concentrations being progressively higher for $\mathrm{C}_{11: 0}$ and $\mathrm{C}_{17: 0}$ standards in the $2 \% \mathrm{FA} / \mathrm{DE}$ solution. This demonstrates that this FFA interaction with the stationary phase appears to increase with carbon chain length. This was further investigated. The quantification of FFA in blank (heptane) injections was analyzed in between FFA standards $\left(\mathrm{C}_{5: 0}, \mathrm{C}_{11: 0}\right.$, and $\left.\mathrm{C}_{17: 0}\right)$ from 50 to $500 \mathrm{mg} / \mathrm{L}$ in heptane (Supplemental Table S4; http:// dx.doi.org/10.3168/jds.2015-10795). Both $\mathrm{C}_{11: 0}$ and $\mathrm{C}_{17: 0}$ standards were quantified in the blanks, with $\mathrm{C}_{17: 0}$ recording the highest measurements of 10 to $59 \mathrm{mg} / \mathrm{L}$ $\left(\mathrm{C}_{5: 0}\right.$ was not detected $)$. This clearly demonstrates the memory effect, where overestimation of FFA can occur because of FFA adsorption onto the column phase from the previous injection, and the effect is more apparent with increasing carbon chain length of the FFA.

\section{Summary of Retention Time Shift and Memory Effect.}

Overall, the memory effect and the use of $2 \% \mathrm{FA} /$ DE on FFA retention times and responses have a significant effect on the analytical robustness of the direct injection on-column method. Because of the $2 \% \mathrm{FA} / \mathrm{DE}$ solution inhibiting FFA interaction with the column phase, we employed this solution as a blank injection in between every injection of sample or standard in an effort to reduce or eliminate the memory effect. Also, all calibrations were performed with FFA prepared in this solution to ensure accurate sample measurement.

\section{Optimization of the TMAH FAME Method}

Split Ratio and Injection Volume. The GC conditions used in the direct injection on-column method were unsuitable for the TMAH FAME method because of the large size of the solvent peak, which obscured $\mathrm{C}_{4: 0}$ as shown in Supplemental Figure S3 (http://dx.doi. org/10.3168/jds.2015-10795). Changing the liner to a gooseneck liner and incorporating a split ratio of 1:10 yielded chromatograms with successful identification of all FFA in a standard mix, albeit the response had significantly dropped. Trials were carried out to investigate the optimum split ratios and injection volumes; these were carried out on FFA $\left(\mathrm{C}_{4: 0}-\mathrm{C}_{18: 3}\right)$ prepared in $2 \% \mathrm{FA} / \mathrm{DE}$, which were converted to methyl esters using TMAH. Supplemental Figure S4 (http://dx.doi. org/10.3168/jds.2015-10795) shows the chromatograms of various splits employed using a $0.2-\mu \mathrm{L}$ injection volume and Supplemental Figure S5 (http://dx.doi. org/10.3168/jds.2015-10795) with a $2.0-\mu \mathrm{L}$ injection volume. The differences between the split ratios were evident, with highest responses achieved using a 1:1 split ratio and a $2.00-\mu \mathrm{L}$ injection; however, $\mathrm{C}_{4: 0}$ was again not quantified because of coelution with the solvent peak. The responses obtained on the higher splits were low and may affect the LOD for sample analysis. Therefore a split ratio of $1: 1$ and an injection of $0.2 \mu \mathrm{L}$ offered the best balance of response and quantification of all FFA (although $\mathrm{C}_{4: 0}$ coelutes at the end of the solvent peak, calibration curve data showed a linear response). These instrument conditions were further evaluated in the determination of FFA in infant formula and milk powder dairy samples. The chromatographic separation was good; however, quantification of $\mathrm{C}_{4: 0}$ was difficult as the concentration was very low, and it coeluted with the solvent peak. A high number of artifact peaks was also apparent and must be the result 
of secondary reactions in the sample extract. Juárez et al. (1992) reported the presence of trimethylamine (TMA) in the chromatogram, which could interfere with the analysis of $\mathrm{C}_{6: 0}$ and $\mathrm{C}_{8: 0}$ FAME when using TMAH as the derivatizing agent. Trimethylamine is a natural by-product of the TMAH reaction, and it is likely that the artifact peak, which coeluted between $\mathrm{C}_{4: 0}$ and $\mathrm{C}_{5: 0}$ in the infant formula and milk powder samples, was TMA. This artifact peak was not always present and sometimes split interfering with quantification of other FFA. The concentration of this tentative TMA peak appears to be influenced by the split ratio, the injection volume, and the amount of TMAH used in the derivatization step before injection. It appears that the more sample or TMAH introduced into the GC system (low split ratio, high injection volume, and high amount of TMAH added during sample preparation), the more abundant the artifact TMA peak and, thus, the greater likelihood of it interfering with the analysis. In this method the injector temperature was set at $300^{\circ} \mathrm{C}$ for the reaction to take place to form FAME because Juárez et al. (1992) noted that this temperature yielded optimal results. However, the upper temperature limit of the FFAP column used in this study was $275^{\circ} \mathrm{C}$, so it is possible that this also contributed to artifact peak formation. However, when dealing with high levels of FFA (FAME), these issues are not a significant problem. In an effort to overcome problems quantify samples with low levels of $\mathrm{C}_{4: 0}$, a higher split ratio (1:20) and injection volume $(2.0 \mu \mathrm{L})$ were evaluated. Supplemental Figure S6 (http://dx.doi.org/10.3168/jds.2015-10795) displays a stacked chromatogram comparing the effect of these new parameters on a standard mix at $50 \mathrm{mg} / \mathrm{L}$. The higher split ratio removes a lot of the artifact peak formation. Although the overall response was lower, baseline noise was reduced, and thus the LOD should not be compromised.

Figure 4 shows a standard mix at $400 \mathrm{mg} / \mathrm{L}$, using a 1:20 split and a $2.0-\mu \mathrm{L}$ injection. Free fatty acid $\mathrm{C}_{4: 0}$ was successfully identified, and the tentative TMA peak was no longer present. Although in some analysis this peak was intermittently detected under these conditions, its interference was markedly reduced. Overall a 1:20 split over 1:1 appears more suitable for TMAH FAME analysis, yielding a cleaner chromatogram with fewer interfering artifact peaks. The overall response decreased under these conditions, but a more stable baseline with less interfering peaks was generated,

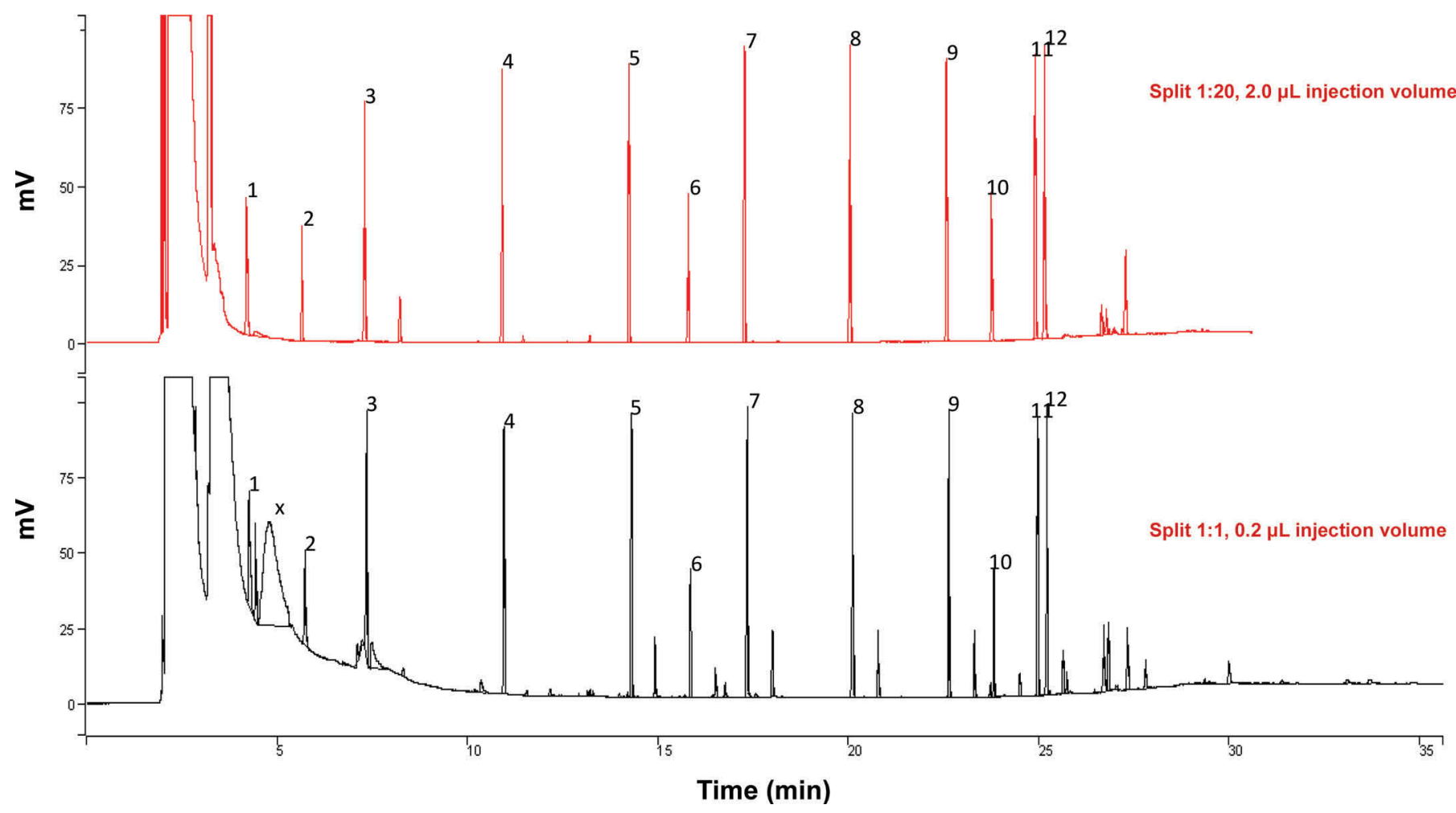

Figure 4. Stacked chromatograms showing analyses of FAME, at $400 \mathrm{mg} / \mathrm{L}$. Internal standards (ISTD) are present at $200 \mathrm{mg} / \mathrm{L}$. A comparison is shown of a $0.2-\mu \mathrm{L}$ injection volume with a 1:1 split and a $2.0-\mu \mathrm{L}$ injection volume with a 1:20 split. Peaks are $1=$ methyl butyrate; $\mathrm{x}=$ unknown (believed to be trimethylamine); $2=$ methyl valerate (ISTD); $3=$ methyl capronate; $4=$ methyl caprylate; $5=$ methyl caprate; $6=$ methyl undecanoate (ISTD); $7=$ methyl laurate; $8=$ methyl myristate $9=$ methyl palmitate; $10=$ methyl heptadecanoate $($ ISTD); $11=$ methyl stearate; $12=$ methyl oleate. Color version available online. 
which should have a more positive effect on the LOD achieved. The quantification of $\mathrm{C}_{4: 0}$ was also improved because of the decreased solvent peak.

Effect of TMAH Volume. The amount of TMAH used during the derivatization step is an important factor. Insufficient TMAH may result in incomplete derivatization of FFA; thus, the effect of TMAH volume on responses obtained during analysis was also investigated. A standard of $300 \mu \mathrm{L}$ containing all FFA at 200 $\mathrm{mg} / \mathrm{L}$ in $2 \% \mathrm{FA} / \mathrm{DE}$ was used. The following amounts of TMAH $(60,120,180$, and $240 \mu \mathrm{L})$ and deionized water $(300,240,180$, and $120 \mu \mathrm{L})$ were added to the standard so that the final volume was always $660 \mu \mathrm{L}$. Comparison of the resultant chromatograms showed an increase in response as the amount of TMAH increased. Supplemental Table S5 (http://dx.doi.org/10.3168/ jds.2015-10795) shows the area responses obtained from the individual FAME in each solution. One trend observed was that the overall response increased with the amount of TMAH added. This would suggest that complete derivatization does not occur at the lower volumes of TMAH and underivatized FFA remains. Normally, it would be prudent to add the highest amount of TMAH to ensure complete derivatization, but as previously discussed the formation of artifact peaks, such as TMA, interferes with the analysis of some of the short-chain FFA. Supplemental Figure S7 (http:// dx.doi.org/10.3168/jds.2015-10795) is the comparison of 2 of the chromatograms obtained, one with $60 \mu \mathrm{L}$ of TMAH and the other with $240 \mu \mathrm{L}$ of TMAH. The development of the tentatively identified TMA peak was evident. It also appears that sometimes the TMA peak splits (an intermittent occurrence), leading to interference with $\mathrm{C}_{6: 0}$, which has not been previously reported. Once linearity is achieved with consistency, complete derivatization of all FFA is not necessary; rather, the goal is to use conditions that yield reproducible results and minimize all possible interference from artifacts that may adversely affect quantification of FAME. The TMA formation was reduced with $60-\mu \mathrm{L}$ TMAH volume, and all subsequent analyses of dairy products in this study were carried out using $60 \mu \mathrm{L}$ of TMAH per $300 \mu \mathrm{L}$ of sample extract or standard, with a high level of linearity being achieved.

FAME Interaction with Column Phase. It was apparent from initial analysis that FAME were not as susceptible to carryover as FFA. Although analysis of blank injections (Supplemental Figure S8; http:// dx.doi.org/10.3168/jds.2015-10795) analyzed after a standard with FAME present at $700 \mathrm{mg} / \mathrm{L}$ had some identifiable FFA, the responses from these peaks were very low and often not quantifiable in contrast to the direct injection on-column method. Although sample carryover is still a concern for the TMAH FAME meth- od, the analysis of methyl esters is not as susceptible to the memory effect as the direct injection on-column method.

Detection of PUFA $C_{18: 2}$ and $C_{18: 3}$. A noticeable difference between the direct injection on-column method and the TMAH FAME method is the apparent loss of PUFA, $\mathrm{C}_{18: 2}$ and $\mathrm{C}_{18: 3}$ with the TMAH FAME method. Tetramethylammonium hydroxide is a strong base, and its use as an esterification reagent has been shown to cause degradation of PUFA (Downing and Greene, 1968; MacGee and Allen, 1974), which can be overcome by neutralizing the solution to $\mathrm{pH} 7.5$ to 8.0. The effect of neutralizing the solution was investigated by Martínez-Castro et al. (1986); however, they discovered that losses of short-chain fatty acids occurred and precision deteriorated. This was attributed to the ammonium salts of FFA dissociating at the lower $\mathrm{pH}$, and they found more reproducible results when neutralization was not employed. Therefore in this study we did not neutralize the solution after the addition of TMAH, because PUFA generally only constitute a minor fraction of FFA in dairy products, to ensure analytical robustness and sensitivity for the detection of short-chain fatty acids.

\section{Method Validation}

Linearity. The linearity of both methods was investigated where the FFA were prepared as described previously. For the direct injection on-column method, the linear range was 3 to $700 \mathrm{mg} / \mathrm{L}$ and 20 to $700 \mathrm{mg} / \mathrm{L}$ for the TMAH FAME method. Tables 2 and 3 show the calibration data obtained for both methods where line equation, correlation coefficient, and linear range are illustrated. Both methods display linearity over these concentration ranges, where correlation coefficients of $\geq 0.999$ were achieved for almost all FFA.

$\boldsymbol{L O D}$ and $\boldsymbol{L O Q}$. The LOD and LOQ were evaluated based on the signal-to-noise ratio as well as by performing quantitation on serial dilutions on a FFA mixture with a sample number equal to $6(\mathrm{n}=6)$. Given the range of acids analyzed, these thresholds were established based on the response obtained from $\mathrm{C}_{4: 0}$, because of its inherent volatility and having the lowest FID response of all the fatty acids evaluated. Thus, any threshold established for this acid should be well within the detection limits of any of the longer-chain fatty acids. Tables 2 and 3 illustrate the LOD and LOQ thresholds for both methods. The LOD and LOQ were established at 0.7 and $3 \mathrm{mg} / \mathrm{L}$ for the direct injection on-column method (with some exception, see below) and 5 and $20 \mathrm{mg} / \mathrm{L}$ for the TMAH FAME method. Because of the memory effect experienced with the direct injection on-column method, it was impossible 
Table 2. Calibration curve data for free fatty acids by the direct injection on-column method

\begin{tabular}{llcccc}
\hline $\begin{array}{l}\text { Fatty } \\
\text { acid }\end{array}$ & Line equation & $\begin{array}{c}\text { Linear } \\
\text { range } \\
(\mathrm{mg} / \mathrm{L})\end{array}$ & $\begin{array}{c}\text { Correlation } \\
\text { coefficient } \\
\left(\mathrm{R}^{2}\right)\end{array}$ & $\begin{array}{c}\text { LOD } \\
(\mathrm{mg} / \mathrm{L})\end{array}$ & $\begin{array}{c}\text { LOQ } \\
(\mathrm{mg} / \mathrm{L})\end{array}$ \\
\hline $\mathrm{C}_{4: 0}$ & $y=0.8741 x-0.0001$ & $3-700$ & 0.9999 & 0.7 & 3 \\
$\mathrm{C}_{6: 0}$ & $y=1.0994 x-0.0191$ & $3-700$ & 0.9998 & 0.7 & 3 \\
$\mathrm{C}_{8: 0}$ & $y=1.1734 x-0.0249$ & $3-700$ & 0.9997 & 0.7 & 3 \\
$\mathrm{C}_{10: 0}$ & $y=1.0548 x-0.0055$ & $3-700$ & 0.9999 & 0.7 & 3 \\
$\mathrm{C}_{12: 0}$ & $y=1.0960 x-0.0065$ & $3-700$ & 0.9999 & 0.7 & 3 \\
$\mathrm{C}_{14: 0}$ & $y=1.1119 x-0.0072$ & $3-700$ & 0.9999 & 0.7 & 3 \\
$\mathrm{C}_{16: 0}$ & $y=1.1211 x+0.0138$ & $3-700$ & 0.9999 & $\mathrm{NA}$ & 20 \\
$\mathrm{C}_{18: 0}$ & $y=0.9960 x-0.0123$ & $3-700$ & 0.9998 & $\mathrm{NA}$ & 20 \\
$\mathrm{C}_{18: 1}$ & $y=1.0348 x-0.0132$ & $3-700$ & 0.9998 & 0.7 & 3 \\
$\mathrm{C}_{18: 2}$ & $y=0.9986 x-0.0180$ & $3-700$ & 0.9998 & 0.7 & 3 \\
$\mathrm{C}_{18: 3}$ & $y=0.9427 x-0.0274$ & $3-700$ & 0.9994 & 0.7 & 3 \\
\hline
\end{tabular}

${ }^{1} \mathrm{LOD}=$ limit of detection; $\mathrm{LOQ}=$ limit of quantification; $\mathrm{NA}=$ not applicable.

to establish a LOD for $\mathrm{C}_{16: 0}$ and $\mathrm{C}_{18: 0}$ because of their propensity to absorb onto the FFAP column phase and their relative high concentration in dairy samples. This also influenced the LOQ determination because quantifiable results could not be reliably achieved below 20 $\mathrm{mg} / \mathrm{L}$, whereas for the other acids the LOQ was established at $3 \mathrm{mg} / \mathrm{L}$ for this method. As anticipated the thresholds were higher in the TMAH FAME method due to the difference in the sample introduction between both methods (split versus on-column injection) and because the solvent peaks obscures the $\mathrm{C}_{4: 0}$ methyl ester at low concentrations (the $\mathrm{C}_{4: 0}$ methyl ester could not be detected below $5 \mathrm{mg} / \mathrm{L}$, and reliable quantification could not be achieved below $20 \mathrm{mg} / \mathrm{L}$ ).

Accuracy. The accuracy of both methods was expressed as the relative error $(\mathbf{R E})$ of each FFA $\left(\mathrm{C}_{4: 0^{-}}\right.$ $\mathrm{C}_{18: 3}$ ) across a concentration range of 20 to $700 \mathrm{mg} / \mathrm{L}$. The RE is based on the true value of the FFA in solution compared with the value obtained from the analysis. Table 4 shows the average values obtained from the analyses of 9 calibration curves, along with the residual standard deviation (RSD). A high error was experienced with the direct injection on-column method: a $35 \% \mathrm{RE}$ for $\mathrm{C}_{18: 2}$, a $20 \% \mathrm{RE}$ for $\mathrm{C}_{18: 0}$, and $25 \% \mathrm{RE}$ for $\mathrm{C}_{16: 0}$ at $20 \mathrm{mg} / \mathrm{L}$. The quantification of these acids as previously discussed is adversely influenced by the memory effect, which is more apparent for longer-chain acids at concentrations $\leq 20 \mathrm{mg} / \mathrm{L}$. The error experienced decreased as the concentration increased (100$700 \mathrm{mg} / \mathrm{L}$ ): 10.1 to $14.0 \% \mathrm{RE}$ for $\mathrm{C}_{16: 0}, 1.7$ to $7.0 \% \mathrm{RE}$ for $\mathrm{C}_{18: 0}, 4.0$ to $7.1 \% \mathrm{RE}$ for $\mathrm{C}_{18: 1}$, and 7.0 to $10.2 \% \mathrm{RE}$ for $\mathrm{C}_{18: 2}$. The $\mathrm{RE}$ for $\mathrm{C}_{8: 0}$ was also high at $20 \%$ for low concentrations. The high RE observed with the direct injection on-column method for the long-chain acids is in contrast to the RE values achieved for these same FA using TMAH FAME analysis (1.6-17.7\% RE for $\mathrm{C}_{16: 0}$ and 1.0-2.4 RE for $\mathrm{C}_{18: 1}$ ). These data clearly highlight the differences in interaction between the FFA and FAME with the FFAP column phase. Also RE values of $80 \%$ were achieved for $\mathrm{C}_{18: 3}$ at $20 \mathrm{mg} / \mathrm{L}$ and $36 \%$ at $100 \mathrm{mg} / \mathrm{L}$ using the direct injection on-column method. Band broadening of the late eluting peaks, particularly during the latter stages of column lifetime, was also a feature of the direct injection on-column method. This resulted in a reduced signal making peak integration more difficult, which adversely affected accuracy. At 300 to $700 \mathrm{mg} / \mathrm{L}$ the $\mathrm{RE}$ improved to 3.0 to $14.3 \%$ for $\mathrm{C}_{18: 3}$. A newer column would yield more accurate results

Table 3. Calibration curve data for methyl esters produced using the tetramethylammonium hydroxide FAME method $^{1}$

\begin{tabular}{llcccc}
\hline FAME & Line equation & $\begin{array}{c}\text { Linear } \\
\text { range } \\
(\mathrm{mg} / \mathrm{L})\end{array}$ & $\begin{array}{c}\text { Correlation } \\
\text { coefficient } \\
\left(\mathrm{R}^{2}\right)\end{array}$ & $\begin{array}{c}\text { LOD } \\
(\mathrm{mg} / \mathrm{L})\end{array}$ & $\begin{array}{c}\text { LOQ } \\
(\mathrm{mg} / \mathrm{L})\end{array}$ \\
\hline $\mathrm{C}_{4: 0}$ & $y=0.9031 x-0.0338$ & $20-700$ & 0.9978 & 5 & 20 \\
$\mathrm{C}_{6: 0}$ & $y=1.2096 x+0.0212$ & $20-700$ & 0.9995 & 5 & 20 \\
$\mathrm{C}_{8: 0}$ & $y=1.3365 x+0.0125$ & $20-700$ & 0.9997 & 5 & 20 \\
$\mathrm{C}_{10: 0}$ & $y=1.0610 x+0.0091$ & $20-700$ & 0.9999 & 5 & 20 \\
$\mathrm{C}_{12: 0}$ & $y=1.0959 x+0.0107$ & $20-700$ & 0.9998 & 5 & 20 \\
$\mathrm{C}_{14: 0}$ & $y=1.1078 x+0.0095$ & $20-700$ & 0.9998 & 5 & 20 \\
$\mathrm{C}_{16: 0}$ & $y=1.0837 x+0.0001$ & $20-700$ & 0.9999 & 5 & 20 \\
$\mathrm{C}_{18: 0}$ & $y=1.0694 x+0.0036$ & $20-700$ & 0.9999 & 5 & 20 \\
$\mathrm{C}_{18: 1}$ & $y=1.0491 x+0.0137$ & $20-700$ & 0.9998 & 5 & 20 \\
\hline
\end{tabular}

${ }^{1} \mathrm{LOD}=$ limit of detection; $\mathrm{LOQ}=$ limit of quantification. 
at low concentrations, but this was not a realistic representation for routine analysis. Hence, this accuracy study was performed at roughly mid FFAP column lifetime. An example of how column degradation affects chromatography is demonstrated in Supplemental Figure S9 (http://dx.doi.org/10.3168/jds.2015-10795). A relatively high RSD of $19.8 \%$ was achieved for $\mathrm{C}_{4: 0}$ at $20 \mathrm{mg} / \mathrm{L}$, for the TMAH FAME method, despite achieving $2.9 \% \mathrm{RE}$ from the replicates. This level of deviation highlights the influence of the $\mathrm{C}_{4: 0}$ methyl esters proximity to the solvent peak where peak integration becomes more difficult at low concentrations.

Precision. The precision of both methods was established by assessing the repeatability of a $100 \mathrm{mg} / \mathrm{L}$ standard, containing all FFA $\left(\mathrm{C}_{4: 0}-\mathrm{C}_{18: 3}\right)$ in $2 \% \mathrm{FA} /$ DE. This was either analyzed directly for the direct injection on-column method or converted to methyl esters using TMAH for the TMAH FAME method. Intraday repeatability was established with a sample number of $10(\mathrm{n}=10)$. Because of the memory effect described earlier, it was prudent to observe how this influenced precision. Dairy samples with a high level of FFA were anticipated to have a large effect on the memory effect of the column. The interday study was designed so that certified FFA standards were analyzed throughout the course of the study. Table 5 shows the RSD \% achieved for both methods in the precision study. The number of samples totaled $86(\mathrm{n}=86)$ for the direct injection on-column method and 70 (n $=70$ ) for the TMAH FAME method. Both methods displayed excellent repeatability for the intraday study, with 2.2 to $5.4 \%$ RSD achieved for the direct injection on-column method and 1.3 to $7.2 \%$ RSD for the TMAH method. With the exception of $\mathrm{C}_{4: 0}(7.2 \%$ RSD), the TMAH FAME method had better intraday precision but a poorer interday RSD (from 9.2 to $37.2 \%$ ). The RSD increased (4.5-17.9\%) in the direct injection oncolumn method. For both methods the longer-chain acids $\left(\mathrm{C}_{14: 0}-\mathrm{C}_{18: 0}\right)$ produced the greatest increase in RSD for the interday study, for the direct injection oncolumn method this can be attributed to the memory effect. The poorer performance of the TMAH FAME method on the interday study was unexpected because the analysis of methyl esters did not appear to have a memory effect as evident from the validation studies. Thus, this increased variance could not be attributed solely to sample carryover during analysis. Subsequent investigations found that this variance was related to the injector (Varian 1079 injector) and liner (Gooseneck liner) employed. Issues with regard to pyrolytic methylation have been previously identified (Robb and Westbrook, 1963; Martínez-Castro et al., 1986), where incomplete or slow methylation occurred because of cold spots in the injector and because of dead volumes in the injector. This was evident by poor peak shape due to the slow formation of the methyl ester within the injector (Martínez-Castro et al., 1986), something that was not observed in this study. The poor RSD in the TMAH FAME method was possibly due to ineffectual sample mixing in the liner under the split conditions described. Replacing the liner with a wool packed liner resulted in better reproducibility (results not shown), and it appears that the wool packing provides a more stable platform for the TMAH reaction to proceed under the described split conditions, although a more comprehensive study is required to confirm this.

\section{Quantification of Dairy Samples by both Methods}

Recovery Determination. Recovery determinations were established by the addition of a known amount of FFA to each sample. These spiked samples were compared against unspiked (normal) samples, where the difference was used to calculate the amount of FFA recovered during the extraction steps and the results are displayed in Tables 6,7 , and 8 . The highest level of recoveries (>92\%) were obtained from the cheese samples (light Cheddar, mild Cheddar, mature Cheddar, Brie cheese), infant formula, and milk powder samples. Lower recoveries $(<90 \%)$ were achieved for milk, ice cream, yogurt, Blue Stilton cheese, and butter samples. Both methods displayed similar results (which is not surprising because the same FFA extraction method was employed in both cases), although there were some exceptions. Enzyme modified cheese samples consisted of 2 powders (natural cream and natural butter) and 3 pastes (natural cream, natural butter, and natural blue cheese) and had a higher variance in their respective recoveries for both methods. The extremely high level of FFA in these samples resulted in severe carryover between samples, which was particularly evident in the direct injection on-column method. As discussed previously this memory effect is more evident with the longer-chain acids $\left(>\mathrm{C}_{16: 0}\right)$. Because $\mathrm{C}_{16: 0}$ is one of the most abundant acids in dairy fat (24.88-26.20\% reported by Jensen et al., 1991), its higher level leads to errors in recovery determinations for most samples. Other samples with high levels of $\mathrm{C}_{16: 0}$, such as Blue Stilton cheese, achieved recoveries of 56 and $63 \%$, and special reserve mature Cheddar cheese had recoveries of 72 and $60 \%$, for the direct injection on-column and TMAH FAME methods, respectively. This is in contrast to the recoveries achieved with the short-chain FFA $\left(\mathrm{C}_{4: 0}-\mathrm{C}_{8: 0}\right)$, which where $>95 \%$ for both methods, despite the fact that these short-chain acids tend to cause problems due to their high volatility and water solubility. Long-chain acid recovery tended to increase when dealing with samples with lower concentrations 
Table 4. Accuracy determination for both methods ${ }^{1}$

\begin{tabular}{|c|c|c|c|c|c|c|c|}
\hline Fatty acid & T. Conc. (mg/L) & \multicolumn{3}{|c|}{ Direct injection method } & \multicolumn{3}{|c|}{ TMAH FAME Method } \\
\hline \multirow[t]{5}{*}{$\mathrm{C}_{4: 0}$} & 20 & 21 & 5.0 & 9.0 & 19 & 2.9 & 19.8 \\
\hline & 100 & 100 & 0.0 & 8.9 & 95 & 5.2 & 4.7 \\
\hline & 300 & 299 & 0.3 & 8.9 & 291 & 2.9 & 3.7 \\
\hline & 500 & 498 & 0.4 & 8.9 & 518 & 3.7 & 3.8 \\
\hline & 700 & 682 & 2.6 & 9.0 & 708 & 1.2 & 4.0 \\
\hline \multirow{3}{*}{$\mathrm{C}_{6: 0}$} & 300 & 280 & 6.7 & 10.5 & 307 & 2.3 & 5.4 \\
\hline & 500 & 468 & 6.4 & 10.4 & 522 & 4.4 & 6.1 \\
\hline & 700 & 674 & 3.7 & 10.4 & 726 & 3.7 & 6.3 \\
\hline \multirow[t]{4}{*}{$\mathrm{C}_{8: 0}$} & 20 & 16 & 20.0 & 6.4 & 23 & 15.5 & 7.3 \\
\hline & 100 & 84 & 16.0 & 6.4 & 106 & 6.1 & 8.4 \\
\hline & 300 & 263 & 12.3 & 6.4 & 312 & 4.0 & 7.4 \\
\hline & 500 & 444 & 11.2 & 6.4 & 528 & 5.6 & 7.9 \\
\hline $\mathrm{C}_{10: 0}$ & 700 & 781 & 11.6 & 5.9 & 715 & 2.2 & 4.3 \\
\hline \multirow{5}{*}{$\mathrm{C}_{12: 0}$} & 20 & 20 & 0.0 & 5.9 & 22 & 9.2 & 7.7 \\
\hline & 100 & 108 & 8.0 & 5.9 & 102 & 2.4 & 8.5 \\
\hline & 300 & 330 & 10.0 & 5.9 & 303 & 0.9 & 2.8 \\
\hline & 500 & 550 & 10.0 & 5.8 & 513 & 2.6 & 3.9 \\
\hline & 700 & 769 & 9.9 & 5.9 & 713 & 1.8 & 3.7 \\
\hline \multirow{5}{*}{$\mathrm{C}_{14: 0}$} & 20 & 20 & 0.0 & 5.7 & 22 & 10.6 & 7.5 \\
\hline & 100 & 108 & 8.0 & 5.7 & 99 & 0.7 & 12.7 \\
\hline & 300 & 329 & 9.7 & 5.6 & 303 & 1.0 & 2.3 \\
\hline & 500 & 549 & 9.8 & 5.5 & 511 & 2.2 & 3.5 \\
\hline & 700 & 767 & 9.6 & 5.7 & 710 & 1.4 & 3.3 \\
\hline \multirow[t]{3}{*}{$\mathrm{C}_{16: 0}$} & 20 & 25 & 25.0 & 6.5 & 24 & 17.7 & 9.8 \\
\hline & 100 & 114 & 14.0 & 6.3 & 108 & 7.7 & 8.0 \\
\hline & 300 & 338 & 12.7 & 6.5 & 305 & 1.7 & 3.3 \\
\hline \multirow{3}{*}{$\mathrm{C}_{18: 1}$} & 300 & 317 & 5.7 & 8.0 & 303 & 0.9 & 1.8 \\
\hline & 500 & 525 & 5.0 & 7.2 & 508 & 1.5 & 2.3 \\
\hline & 700 & 750 & 7.1 & 7.2 & 707 & 1.0 & 3.2 \\
\hline \multirow[t]{5}{*}{$\mathrm{C}_{18: 2}$} & 20 & 13 & 35.0 & 7.8 & $\mathrm{ND}^{2}$ & ND & ND \\
\hline & 100 & 93 & 7.0 & 8.6 & ND & ND & ND \\
\hline & 300 & 323 & 7.7 & 8.8 & ND & ND & ND \\
\hline & 500 & 551 & 10.2 & 8.4 & ND & ND & ND \\
\hline & 700 & 766 & 9.4 & 8.3 & ND & ND & ND \\
\hline \multirow{5}{*}{$\mathrm{C}_{18: 3}$} & 20 & 4 & 80.0 & 10.6 & ND & ND & ND \\
\hline & 100 & 64 & 36.0 & 15.6 & ND & ND & ND \\
\hline & 300 & 309 & 3.0 & 11.7 & ND & ND & ND \\
\hline & 500 & 549 & 9.8 & 11.3 & ND & ND & ND \\
\hline & 700 & 800 & 14.3 & 11.1 & ND & ND & ND \\
\hline
\end{tabular}

${ }^{1}$ Data show the average results obtained from 9 calibration curves. T. Conc. $=$ true concentration; M. Conc. $=$ measured concentration; RE $=$ relative error; $\mathrm{RSD}=$ relative $\mathrm{SD} ; \mathrm{TMAH}=$ tetramethylammonium hydroxide.

${ }^{2} \mathrm{ND}=$ not detected.

of FFA. Milk powder, which had a total FFA concentration of 337 and $333 \mathrm{mg} / \mathrm{L}$ for the direct injection on-column and TMAH FAME methods, respectively, had $\mathrm{C}_{16: 0}$ recoveries of $>96 \%$.
Sample Analysis. The degree of variance achieved for both methods was expressed as \% RSD obtained between sample replicates $(\mathrm{n}=6)$. Both methods were comparable to each other, and excellent RSD values 
were achieved. For the analysis of the cheese samples, total RSD of 0.9 to $6.9 \%$ was achieved for the direct injection on-column method and of 0.8 to $13.8 \%$ for the TMAH FAME method. For the EMC total RSD ranged from 0.9 to $8.3 \%$ for the direct on-column injection method and from 0.9 to $8.8 \%$ for the TMAH FAME method.

Total RSD values ranged from 0.8 to $8.5 \%$ for milk powder, 7.4 to $9.6 \%$ for infant formula, and 7.2 to $10.9 \%$ for butter samples for the direct on-column injection and TMAH FAME methods, respectively. The highest RSD variance observed was for the yogurt $(4.8 \%$, $34.6 \%$ ), ice cream $(9.5 \%, 22.0 \%)$, and milk samples $(46.6 \%, 45.8 \%)$ for the direct injection on-column and TMAH FAME methods, respectively. In terms of individual FFA, high levels of variance were observed for most FFA determined in milk, with RSD values of 69.1 and $42.1 \%$ for $\mathrm{C}_{12: 0}$ and 83.0 and $66.7 \%$ for $\mathrm{C}_{14: 0}$ for the direct injection on-column and TMAH FAME methods, respectively. The higher deviations observed for the yogurt, milk, and ice cream are likely due to the extraction method, which appears less suitable for nonsolid products, as De Jong and Badings (1990) had described a different extraction procedure for milk and subsequently for yogurt (De Jong et al., 1994). This may be attributed to the influence of the lipoprotein complex and the intact structure of the milk fat globule membrane (IDF 1991) in these dairy samples as opposed to others were the membrane is less intact or completely disrupted. For milk, solvent extraction is generally not successful without employing a suitable reagent to break up the lipoprotein complex, such as described in the copper soap method (Shipe et al., 1980; Firl et al., 2014). De Jong and Badings (1990) employed ethanol during the solvent extraction of milk and reported \% RSD values of individual FFA ranging from 1.7 to $0.5 \%$. Ethanol has also been used in FFA determinations of yogurt, with reported RSD of 1.2 to 3.6\% (De Jong et al., 1994; Rychlik et al., 2006), and in ice cream (Shotwell et al., 1953), although no individual FFA determinations were provided. Although the addition of a solvent such as ethanol should yield better results for yogurt, ice cream, and milk, for comparison purposes the same extraction procedure was employed across all samples in this study.

Other notable differences exist in the behavior of certain fatty acids between both methods. Determination of the short-chain acids when present at low levels proved more problematic in some samples using the TMAH FAME method. This was especially apparent for the milk powder and infant formula samples, where the concentration of the short-chain acids was very low. For milk powder, deviations for $\mathrm{C}_{6: 0}$ and $\mathrm{C}_{8: 0}$ were 24.3 and $19.0 \%$, respectively, and $\mathrm{C}_{4: 0}$ was not detected using the TMAH FAME method, yet $\mathrm{C}_{4: 0}$ was present as evident by the result of the direct injection on-column method. The fact that $\mathrm{C}_{4: 0}$ could not be quantified at low concentrations by the TMAH FAME method was because of the reduced retention time of methyl esters where $\mathrm{C}_{4: 0}$ coeluted with the solvent peak. Also, an artifact peak, believed to be TMA, sometimes coeluted with $\mathrm{C}_{6: 0}$ methyl esters, which occurred in the analysis of the Brie cheese and processed cheese samples resulting in \% RSD values $>100 \%$ between these replicates. However, this trend was not observed with higher FFA concentrations, where the results from the 2 methods were more comparable.

\section{CONCLUSIONS}

The direct injection on-column method has a lower detection and quantification level because of the on-col-

Table 5. Intraday and interday repeatability study for both methods ${ }^{1}$

\begin{tabular}{|c|c|c|c|c|}
\hline \multirow[b]{2}{*}{ Fatty acid } & \multicolumn{2}{|c|}{ Direct injection method } & \multicolumn{2}{|c|}{ TMAH FAME method } \\
\hline & Intraday RSD (\%) & Interday RSD (\%) & Intraday RSD (\%) & Interday RSD (\%) \\
\hline $\mathrm{C}_{4: 0}$ & 3.6 & 4.5 & 7.2 & 16.4 \\
\hline $\mathrm{C}_{6: 0}$ & 4.4 & 5.7 & 1.9 & 12.3 \\
\hline $\mathrm{C}_{8: 0}$ & 4.1 & 6.3 & 2.0 & 10.6 \\
\hline $\mathrm{C}_{10: 0}$ & 4.1 & 11.2 & 1.4 & 9.2 \\
\hline $\mathrm{C}_{12: 0}$ & 3.7 & 14.0 & 2.3 & 13.7 \\
\hline $\mathrm{C}_{14: 0}$ & 2.7 & 17.9 & 4.3 & 25.3 \\
\hline $\mathrm{C}_{16: 0}$ & 2.2 & 14.1 & 1.3 & 37.2 \\
\hline $\mathrm{C}_{18: 0}$ & 3.8 & 15.0 & 1.5 & 20.9 \\
\hline $\mathrm{C}_{18: 1}$ & 4.4 & 10.5 & 1.5 & 30.3 \\
\hline $\mathrm{C}_{18: 2}$ & 5.4 & 7.3 & $\mathrm{ND}^{2}$ & ND \\
\hline $\mathrm{C}_{18: 3}$ & 4.3 & 11.0 & ND & ND \\
\hline
\end{tabular}

${ }^{1}$ Precision is expressed as relative SD (RSD); $\mathrm{n}=10$ for the intraday data for both methods, $\mathrm{n}=86$ for the interday data over 6 mo for the direct injection method, and $n=70$ over 2 mo for the tetramethylammonium hydroxide (TMAH) method. Each fatty acid was analyzed at $100 \mathrm{mg} / \mathrm{L}$ concentration.

${ }^{2} \mathrm{ND}=$ not detected. 


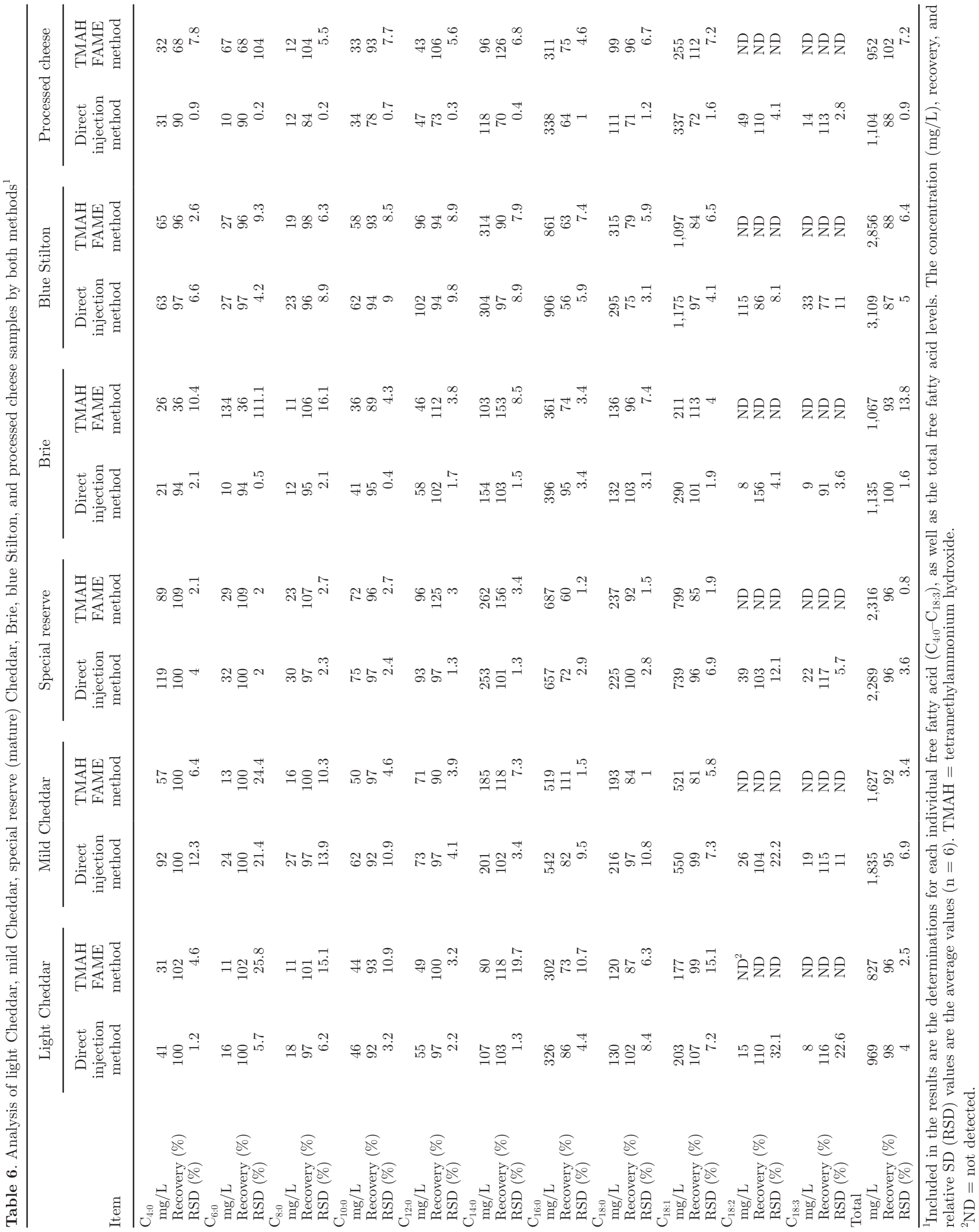




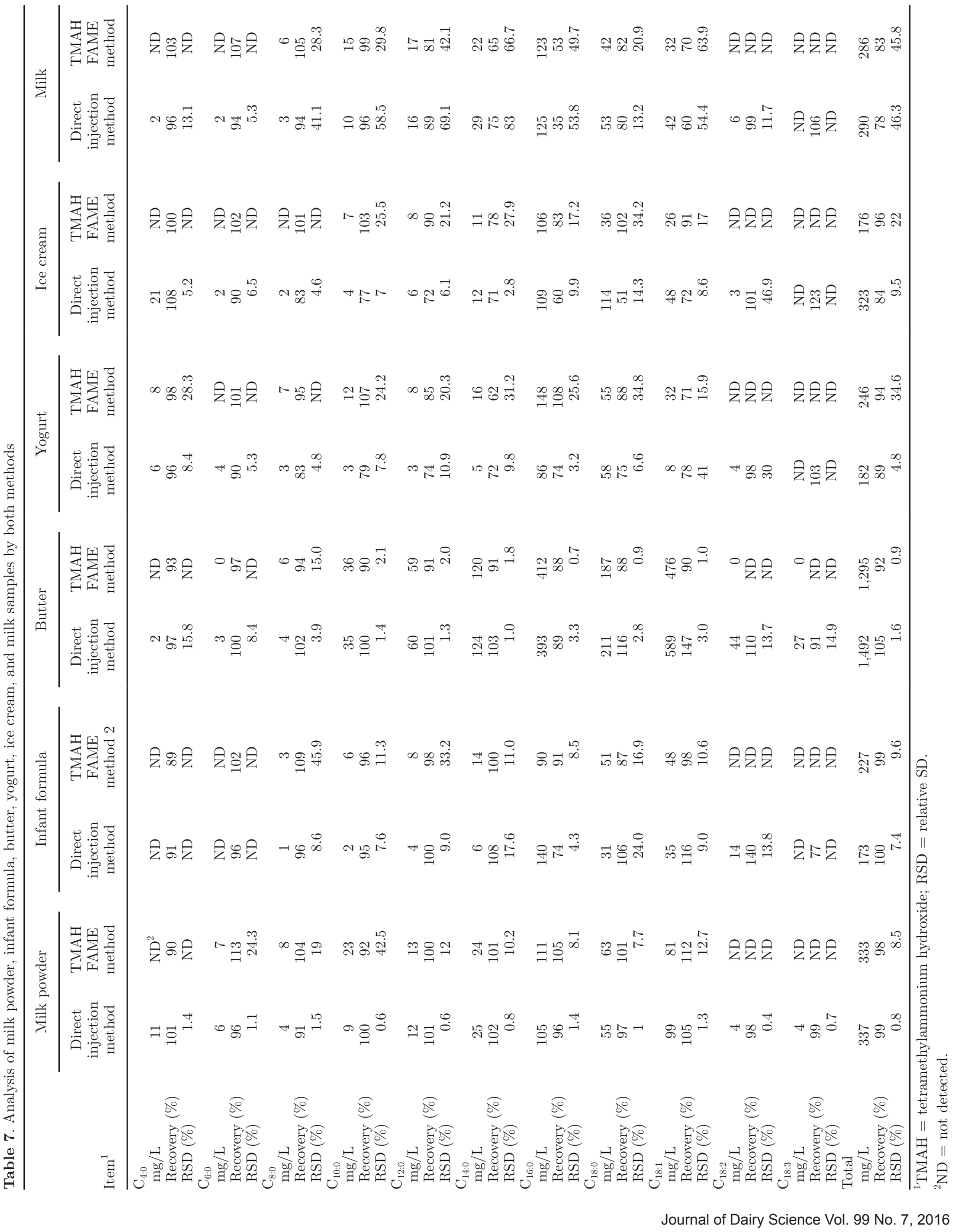




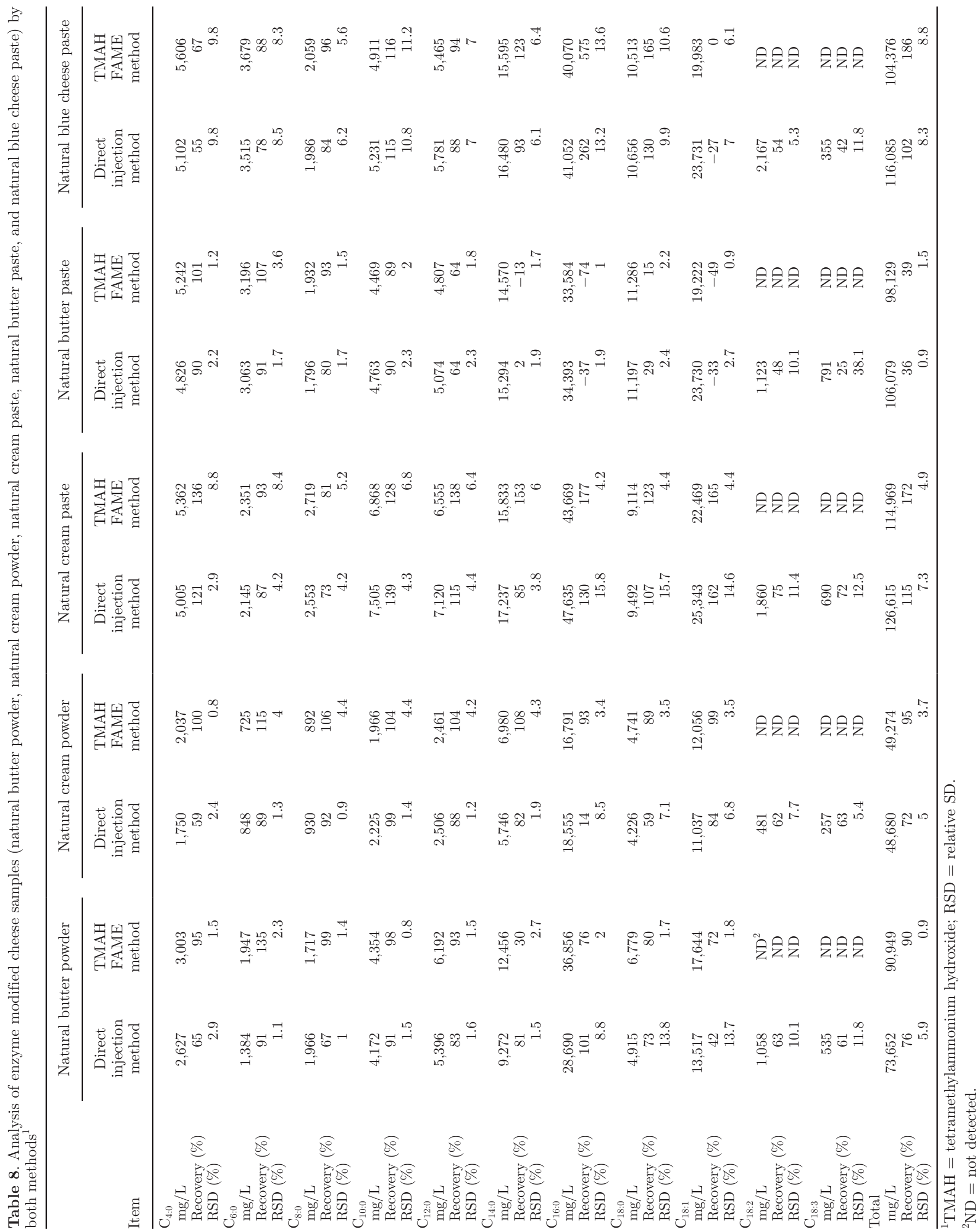


umn injection procedure, but issues with column degradation and lifespan, the memory effect, the requirement for regular maintenance, the need for multiple standard checks and blanks make this method time consuming, expensive, and unsuitable for routine analysis. A significant advantage of the TMAH FAME method over the direct injection on-column method was that column deterioration did not occur and the memory effect was minimal. The earlier elution of the methyl esters allows for quicker run times, but detection of $\mathrm{C} 4: 0$ and $\mathrm{C} 6: 0$ were hindered at low concentrations. Also, PUFA were not quantified using this method. In summary, both methods have advantages and disadvantages, but the TMAH FAME method is more robust. Also, because the derivatization procedure can be automated, it saves time and reduces errors. However, considerable scope remains for further modification or the development of an improved alternative method for FFA analysis of dairy products.

\section{ACKNOWLEDGMENTS}

The authors thank Agilent Technologies Inc. (A Delaware Corporation, Wilmington, DE) for their support of this study.

\section{REFERENCES}

Calzada, J., A. del Olmo, A. Picon, and M. Nuñez. 2014. Effect of high-pressure-processing on lipolysis and volatile compounds of brie cheese during ripening and refrigerated storage. Int. Dairy J. 39:232-239.

Chavarri, F., M. Virto, C. Martin, A. I. Najera, A. Santisteban, L. J. R. Barron, and M. De Renobales. 1997. Determination of free fatty acids in cheese: Comparison of two analytical methods. J. Dairy Res. 64:445-452.

Christie, W. W. 1993. Preparation of ester derivatives of fatty acids for chromatographic analysis. Pages 69-111 in Advances in Lipid Methodology. Vol. 2. W. W. Christie, ed. Oily Press, Dundee, UK.

De Jong, C., and H. T. Badings. 1990. Determination of free fatty acids in milk and cheese procedures for extraction, clean up, and capillary gas chromatographic analysis. J. High Resolut. Chromatogr. 13:94-98.

De Jong, C., K. Palma, and R. Neeter. 1994. Sample preparation before capillary gas-chromatographic estimation of free fatty acids in fermented dairy products. Neth. Milk Dairy J. 48:151-156.

Deeth, H. C., C. H. Fitzgerald, and A. J. Snow. 1983. A gas chromatographic method for the quantitative determination of free fatty acids in milk and milk products. N. Z. J. Dairy Sci. Technol. 18:13-20.

Delmonte, P., A.-R. F. Kia, Q. Hu, and J. I. Rader. 2009. Review of methods for preparation and gas chromatographic separation of trans and cis reference fatty acids. J. AOAC Int. 92:1310-1326.

Downing, D. T., and R. S. Greene. 1968. Methylation of fatty acids by pyrolysis of their tetramethylammonium salts in the gas chromatograph. Anal. Chem. 40:827-828.
Firl, N., H. Kienberger, and M. Rychlik. 2014. Validation of the sensitive and accurate quantitation of the fatty acid distribution in bovine milk. Int. Dairy J. 35:139-144.

Gomes Reis, M., M. M. dos Reis, S. Leath, and K. Stelwagen. 2011. Direct analysis of fatty acid profile from milk by thermochemolysis-gas chromatography-mass spectrometry. J. Chromatogr. A 1218:316-323.

Hickey, D. K., K. N. Kilcawley, T. P. Beresford, E. M. Sheehan, and M. G. Wilkinson. 2006. The influence of a seasonal milk supply on the biochemical and sensory properties of cheddar cheese. Int. Dairy J. 16:679-690.

Hickey, D. K., K. N. Kilcawley, T. P. Beresford, E. M. Sheehan, and M. G. Wilkinson. 2007. Starter strain related effects on the biochemical and sensory properties of cheddar cheese. J. Dairy Res. 74:9-17.

IDF. 1991. Determination of Individual Free Fatty Acids-Reference Method. Bulletin of the IDF 265. Int. Dairy Fed., Brussels, Belgium.

Jensen, R. G., A. M. Ferris, and C. J. Lammi-Keefe. 1991. The composition of milk fat. J. Dairy Sci. 74:3228-3243.

Juárez, M., M. A. de la Fuente, and J. Fontecha. 1992. Improved gas chromatographic method for the determination of the individual free fatty acids in cheese using a capillary column and a ptv injector. Chromatographia 33:351-355.

Kaluzny, M. A., L. A. Duncan, M. V. Merritt, and D. E. Epps. 1985. Rapid separation of lipid classes in high yield and purity using bonded phase columns. J. Lipid Res. 26:135-140.

Kilcawley, K. N., A. B. Nongonierma, J. A. Hannon, I. A. Doolan, and M. G. Wilkinson. 2012. Evaluation of commercial enzyme systems to accelerate cheddar cheese ripening. Int. Dairy J. 26:50-57.

MacGee, J., and K. G. Allen. 1974. Preparation of methyl esters from the saponifiable fatty acids in small biological specimens for gasliquid chromatographic analysis. J. Chromatogr. 100:35-42.

Martin-Hernández, M. C., L. Alonso, M. Juárez, and J. Fontecha. 1988. Gas chromatographic method for determining free fatty acids in cheese. Chromatographia 25:87-90.

Martínez-Castro, I., L. Alonso, and M. Juárez. 1986. Gas chromatographic analysis of free fatty acids and glycerides of milk fat using tetramethylammonium hydroxide as catalyst. Chromatographia $21: 37-40$.

Metcalffe, L., and C. Wang. 1981. Rapid preparation of fatty acid methyl esters using organic base-catalyzed transesterification. J. Chrom. Sci. 19:530-535.

Needs, E. C., G. D. Ford, A. J. Owen, B. Tuckley, and M. Anderson. 1983. A method for the quantitative determination of individual free fatty acids in milk by ion exchange resin adsorption and gasliquid chromatography. J. Dairy Res. 50:321-329.

Robb, E. W., and J. J. Westbrook. 1963. Preparation of methyl esters for gas liquid chromatography of acids by pyrolysis of tetramethylammonium salts. Anal. Chem. 35:1644-1647.

Rychlik, M., M. Sax, and P. Schieberle. 2006. On the role of shortchain free fatty acids for the development of a cheese-like off-note in pasteurized yoghurt. LWT-Food Sci. Technol. (Campinas.) 39:521-527.

Shipe, W. F., G. F. Senyk, and K. B. Fountain. 1980. Modified copper soap solvent extraction method for measuring free fatty acids in milk. J. Dairy Sci. 63:193-198.

Shotwell, T. C., W. J. Harper, and I. A. Gould. 1953. Free fatty acid content of ice cream with certain observations on flavor relationship. J. Dairy Sci. 36:948-954.

Woo, A. H., and R. C. Lindsay. 1982. Rapid method for quantitative analysis of individual free fatty acids in cheddar cheese. J. Dairy Sci. 65:1102-1109. 